\title{
UN DIAGNÓSTICO CONSTITUCIONAL DE LA JUSTICIA TRANSICIONAL EN COLOMBIA
}

\author{
A constitutional diagnosis of \\ transitional justice in Colombia
}

\author{
GERARDO RUIZ-RICO RUIZ' \\ Universidad de Jaén \\ gruiz@ujaen.es
}

Cómo citar/Citation

Ruiz-rico ruiz, G (2018).

Un diagnóstico constitucional de la justicia transicional en Colombia.

Anuario Iberoamericano de Justicia Constitucional, 22, 133-164. doi: https://doi.org/10.18042/cepc/aijc.22.05

\section{Resumen}

Los Acuerdos de Paz firmados en 2016 entre el Estado y las FARC han abierto una etapa histórica en Colombia. La justicia transicional se ha convertido en un instrumento fundamental para la consolidación de la paz y la conciliación en el seno de la sociedad colombiana. A diferencia de la justicia penal ordinaria o institucional, los métodos procesales y sancionatorios que utiliza tienen una finalidad esencialmente restaurativa; no persiguen el castigo sino la reparación de los derechos de las víctimas. El Acto Legislativo aprobado en 2017 en Colombia ha implantado un sistema integral de justicia transicional, compuesto de una Comisión de la Verdad, una Unidad de Desaparecidos y una Justicia Especial para la Paz. La Corte Constitucional colombiana está marcando las condiciones y los límites para la implementación de la justicia transicional.

1 Catedrático de Derecho Constitucional en la Universidad de Jaén. Ha sido director de la Fundación Tres Culturas del Mediterráneo. 


\section{Palabras clave}

Justicia transicional; constitución; Colombia.

\section{Abstrac}

The Peace Agreements signed in 2016 between the State and the FARC have opened a historic period in Colombia. Transitional Justice has become a fundamental instrument for the consolidation of peace and conciliation within Colombian society. Unlike ordinary or institutional criminal justice, the procedural and sanctioning of Transitional Justice have an essentially restorative purpose; they do not pursue punishment but the reparation of the rights of the victims. The Legislative Act approved in 2017 in Colombia has implemented an Integral System of Transitional Justice, composed of a Truth Commission, a Disappeared Unit and a Special Justice for Peace. The Colombian Constitutional Court is setting the conditions and limits for the implementation of transitional justice.

\section{Keywords}

Justice, Constitution, transition, conflicto, Colombia. 


\section{SUMARIO}

I. PRINCIPALES COORDENADAS DEL ITINERARIO DE UNA TRANSICIÓN HACIA LA PAZ EN COLOMBIA. II. LOS PARÁMETROS CONSTITUCIONALES QUE DELIMITAN LA JUSTICIA TRANSICIONAL. III. EL DERECHO CONSTITUCIONAL A LA PAZ COMO PRESUPUESTO LEGITIMADOR DEL PROCESO DE PAZ Y LOS ACUERDOS DE 2016. IV. LA REFORMA DE LA CONSTITUCIÓN COLOMBIANA PARA LA INCORPORACIÓN DE UN SISTEMA DE JUSTICIA TRANSICIONAL. V. EL PAPEL DE LA JURISDICCIÓN CONSTITUCIONAL EN EL PROCESO HACIA LA PAZ Y LA MATERIALIZACIÓN DE LOS ACUERDOS EN EL POSCONFLICTO. BIBLIOGRAFÍA.

\section{PRINCIPALES COORDENADAS DEL ITINERARIO DE UNA TRANSICIÓN HACIA LA PAZ EN COLOMBIA}

El camino hacia la paz en Colombia no ha concluido del todo mientras continúen en activo algunos grupos armados; y especialmente cuando todavía se están implementando por el Gobierno de ese país las medidas previstas en los Acuerdos de Paz de La Habana (septiembre de 2016). Sin embargo, en la actualidad se ha consolidado ya un escenario de posconflicto, donde se inscribe una serie de iniciativas legislativas y gubernamentales, además de un importante número de resoluciones de la Corte Constitucional, de enorme trascendencia para el futuro de la sociedad y el Estado colombianos ${ }^{2}$. El camino hacia la completa pacificación está sujeto aún a compromisos pendientes de ejecución, tanto en la esfera legislativa como en el ámbito de las políticas sociales que ponga en marcha el Estado. Existen de este modo demasiados márgenes de inseguridad en cuanto al momento y los efectos de su definitiva conclusión. El itinerario del proceso de paz se extiende en un dilatado espacio de tiempo, en el que sobresale a su vez una serie de iniciativas políticas, cuya

2 En el proceso hacia la paz y la materialización de los acuerdos en el posconflicto la Corte Constitucional colombiana está jugando un papel esencial. Entre sus pronunciamientos más representativos se pueden mencionar las sentencias C-579, 2013, y C-577, 2014 (sobre el Acto Legislativo 1 de 2012), C-379/16 (referéndum sobre el Acuerdos de Paz de la Habana, o C-699/16, sobre el denominado Fast Track). 
legitimidad va a ser con frecuencia objeto de evaluación por la Corte Constitucional. Sobre ambas esferas jurídicas centraremos el presente análisis.

El principio de la solución del conflicto cabría fijarlo en las últimas negociaciones con las FARC que impulsa el Gobierno colombiano, y que llevan a la aprobación del Acto Legislativo 1/2012, conocido como Marco Jurídico para la $\mathrm{Paz}^{3}$. La norma en cuestión se configuraría como una reforma constitucional, en el marco de la cual se introducirá un conjunto de indicadores, principios e instrumentos característicos de la denominada como «justicia transicional ${ }^{4} »$ : la creación de una Comisión de la Verdad, establecimiento de unas pautas de selección para el procesamiento de los autores de delitos, así como la exclusión para autores no considerados como máximos responsables, y especialmente la adopción de penas alternativas y sanciones extrajudiciales. El Acto Legislativo en cuestión representaría un paso determinante del proceso de paz, ya que facilitaba la negociación que seguidamente se abriría entre Gobierno y FARC, y que concluyó con la firma de los Acuerdos de La Habana en agosto de 2016 (Huérfano-Rueda e Isaza-González, 2017: 164). Pero antes de esa fecha, el Estado colombiano va adoptar además una decisión que será determinante para el éxito de las negociaciones; los pactos que se alcanzarían en las negociaciones con los grupos armados adquirirían finalmente un valor jurídico como canon de constitucionalidad5. De esta forma los Acuerdos de Paz no solo condicionarían en adelante el contenido de cualquier iniciativa

3 Con anterioridad, la Ley de Justicia y Paz de 2005 había previsto ya algunas especialidades procesales, pero no un verdadero sistema de justicia especial transicional, que sin embargo sí está presente en la Ley de víctimas (L. 1448) de 2011. En esta otra norma sí se articulan unos procesos especiales e instrumentos extrajudiciales, con el objetivo de favorecer la reconciliación, la verdad y la paz, mediante la «reparación integral» (art. 8) de los daños causados a las víctimas del conflicto armado.

4 Tomando como fundamento el derecho a la paz (art. 22), se procede con este acto legislativo a introducir un nuevo artículo transitorio 66 en la Constitución Política de Colombia.

5 Su valor jurídico-constitucional va a quedar apuntalado de forma explícita por el Acto Legislativo 1 de 2016. Su art. 4 señalaba que, tras su firma y entrada en vigor, «ingresará en sentido estricto en el bloque de constitucionalidad para ser tenido en cuenta durante el período de implementación de mismo como parámetro y referente de desarrollo y validez de las normas y las Leyes de Implementación y Desarrollo del Acuerdo de Paz». No creemos que el valor que les otorga este precepto suponga la concesión de un estatus superior incluso al de la Constitución Política de 1991, si bien la duda se plantea cuando se les dota de una «rigidez» — diríamos - excepcional, en virtud de la cual se prohíbe su derogación o modificación a través del desarrollo normativo, tanto constitucional como legislativo, que se apruebe por el Congreso. En todo caso, 
política o legislativa que se adoptara por Gobierno y Parlamento; también implicaban la obligación para la propia Corte de interpretar y acomodar todo el ordenamiento jurídico a este nuevo «bloque de constitucionalidad», cuyo contenido sería fijado con los compromisos alcanzados en aquellos acuerdos (Olano-García, 2016: 9) ${ }^{6}$, al que habría que sumar la jurisprudencia elaborada por las Altas Cortes internacionales encargadas de aplicar las principales normas del derecho internacional humanitario y de los derechos humanos, en especial la Corte Interamericana (Prieto San Juan, 2018).

El proceso hacia una pacificación total y estable continuó con la organización de diversas mesas de diálogo (Oslo, Noruega), y finalmente la más decisiva en La Habana, donde se llegó a negociar (2013-2014) una serie de puntos —como la reforma agraria (Pérez Sola, 2018: 327) ${ }^{7}$ y los derechos de participación política ${ }^{8}$ — con los que se prepararía el camino para la firma de los Acuerdos. Durante esta etapa previa e inmediata a la firma de la paz, se aprueban algunas normas legislativas y se adoptan resoluciones institucionales que sin duda facilitarían el acercamiento de las posiciones del Estado y las FARC?.

no parece aceptable atribuir a los actores que participaron en las negociaciones de La Habana el carácter de auténtico poder constituyente.

6 Sin embargo, de este modo no quedaba descartada por completo la posibilidad de que se produjeran conflictos entre los máximos órganos de la justicia ordinaria y la propia Corte Constitucional, con los órganos jurisdiccionales instituidos ex novo por la justicia transicional, creada al efecto para implementar los Acuerdos de Paz.

7 Entre los aspectos que fueron objeto de negociación se planteó ya la necesidad de vincular la paz a una reforma agraria en Colombia, a través de la cual se facilitara el acceso de los campesinos a la propiedad de la tierra, la creación de una jurisdicción agraria que protegiera los derechos de propiedad y la imposición como criterio prevalente del interés común; además de la aprobación futura de instrumentos de planificación en materia de vivienda, educación e infraestructuras.

8 La necesidad de integrar a los grupos armados en los canales de participación política propios de un Estado democrático de derecho se convertiría en un objeto prioritario para consolidar la pacificación en Colombia. De este modo, se trazan desde el principio unas líneas de intervención, orientadas a reforzar la democracia y el pluralismo; la metodología para alcanzar esas metas era, asimismo, diversa: facilitar el ingreso de otras fuerzas políticas en las instituciones representativas, potenciar la participación de la ciudadanía a través de las organizaciones y movimientos sociales, y la reserva de un cierto número de «curiles» en las Asambleas legislativas (Cámara de representantes y Senado) para los representantes de la guerrilla.

9 Se pueden mencionar, entre otras, la decisión del Consejo de Estado (Sentencia 2001, de 29 de abril de 2015) que rechazaría la consideración de las FARC como grupo terrorista; la Ley 1475, de 2014, sobre la regulación y desarrollo de referendos presi- 
Pero para evitar potenciales y futuras situaciones de bloqueo en esta otra esfera, se decidió aplicar una técnica que legitimaba la superioridad normativa de lo acordado en un escenario político, no solo ante el legislador y cualquier otra autoridad pública del Estado, sino incluso frente a la propia Constitución política de 1991. Se pretendió así «blindar» jurídicamente los Acuerdos, otorgándoles un valor como bloque de constitucionalidad; un planteamiento —-más tarde modificado - que tenía unas implicaciones en la esfera jurisdiccional, ya que otorgaba un ámbito competencial a la justicia transicional prácticamente inmune al control de constitucionalidad.

El texto pactado por las partes en conflicto sería firmado en La Habana, y posteriormente sometido a consulta popular (plebiscito) el 2 de octubre de 2016. Podría pensarse que su utilidad a priori se centraba en diseñar un mecanismo contra posibles bloqueos (gubernamentales y jurisdiccionales) en el momento posterior y decisivo de la implementación de los acuerdos (Díaz Gamboa, 2016: 150-158), aunque paradójicamente el fracaso ${ }^{10}$ que se produce la primera y única vez que se activó dejaría en evidencia que existía un riesgo de instrumentalizar la legitimación democrático-popular «directa» para objetivos antagónicos a los de los Acuerdos de Paz.

El triunfo del «no» en el plebiscito forzaría una revisión de su contenido. Ciertamente la escasa participación y la exigua mayoría del electorado que se había pronunciado en contra de su aprobación - 50,21\% de los votos, con una participación por debajo del $50 \%$ del electorado $(37,44 \%)$ - no proporcionaban suficiente legitimación político-constitucional como una

denciales para la terminación del conflicto; y la aprobación de una Ley de Orden Público que establecerá las zonas (las llamadas Zonas Veredales de Normalización) que permitirán el asentamiento y concentración de los miembros de las FARC durante el posconflicto. Cuentan positivamente también en este sentido decisiones adoptadas en la esfera internacional, como la de la Unión Europea, para la creación de un fondo de apoyo para el posconflicto; o la Resolución 2261 del Consejo de Seguridad de la ONU, en la que se decidió la creación de una misión política para la verificación del cese de hostilidades y la entrega de armas.

10 Ciertamente no puede calificarse de otro modo, si se toma como referencia el índice tan reducido de participación, así como el de electores que votaron afirmativamente en favor de la ratificación de los Acuerdos de La Habana. El número de ciudadanos con derecho a voto era de 34899 945. La abstención fue muy elevada: 21833 898, lo que representaba el $62,6 \%$ del electorado colombiano. Los votos afirmativos fueron $6377482(18,3 \%)$, frente a los negativos, superiores en número: 6431376 $(18,4 \%)$. Lo cierto es por tanto que la diferencia a favor del «no» fue tan solo de 53894 votos ( $0,2 \%$ del conjunto del electorado). 
mayoría para bloquear el proceso de paz ${ }^{11}$. El escenario que se abría tras el fracaso del plebiscito obligó a introducir una serie de modificaciones en los pactos inicialmente firmados en La Habana. Entre las más significativas, la vigencia temporal del sistema de justicia transicional de paz, que se fija ahora en unos diez años; asimismo, se establece la supremacía de la Corte Constitucional como jurisdicción «tutelar» que cerraría — después de intentarlo en dos instancias de apelación de la denominada Jurisdicción Especial para la Paz (JEP) - las controversias suscitadas en la aplicación de las medidas gubernamentales para la implementación de los acuerdos; en esta línea se cancela también la concepción «constitucional» de los mismos acuerdos políticos ${ }^{12}$.

\section{LOS PARÁMETROS CONSTITUCIONALES QUE DELIMITAN LA JUSTICIA TRANSICIONAL}

La creación de un sistema de justicia transicional obedece a la necesidad de hacer frente desde el Estado constitucional de derecho a una situación que desborda el sistema penal establecido por el ordenamiento colombiano para situaciones ordinarias y concretas en cuanto a su alcance material y subjetivo (Vega Martinis, 2017). En efecto, la producción «en masa» de delitos que afectan al núcleo fundamental de los derechos humanos y constitucionales exigía la búsqueda de una solución «adaptada» en el plano punitivo y jurisdiccional que ayudara a consolidar el proceso de paz.

La diversidad de metodologías, supuestos fácticos y procedimientos experimentados en diferentes latitudes y países (Duque Ayala, 2016: 19-44) para implementar un sistema de justicia transicional representa una dificultad para elaborar un aparato teórico que permita su aplicación de manera "global», sin tomar en consideración los particularismos de cada caso

11 Se abre así una línea argumental (Marquand, 2016) que considera los Acuerdos de Paz una efectiva limitación al principio de soberanía estatal, al venir configurada aquella en la Constitución colombiana como un «derecho fundamental».

12 Además de determinar claramente la responsabilidad principal del Gobierno en esta tarea. Se contemplan revisiones igualmente importantes que afectaban al ámbito subjetivo de la justicia transicional (también aplicable a policía y fuerzas armadas); la garantía de una integración "política» de los miembros de la guerrilla en el sistema institucional; la desaparición de la llamada «ideología de género» del texto inicial de los Acuerdos, sustituida por una referencia más neutral sobre los derechos de las mujeres víctimas del conflicto; la eliminación de la función acusatoria en los procesos de las organizaciones no gubernamentales, o, entre otras medidas más, la desaparición de jueces extranjeros en el futuro Tribunal de Paz. 
concreto, determinantes para lograr un nivel óptimo de efectividad en su aplicación. Cabría señalar, no obstante, algunos rasgos generales comunes: alternatividad en el sistema sancionatorio, su complementariedad respecto de la justicia penal ordinaria, la temporalidad o el carácter esencialmente restaurativo de las medidas impositivas. En todo caso, se trata de un modelo de justicia basado en la excepcionalidad; tanto por los escenarios sociojurídicos que justifican su adopción como por la diversidad tipológica de medidas extraordinarias (procesos especiales y medidas extrajudiciales) en las que se va a concretar su aplicación.

No obstante, es imposible obviar la responsabilidad penal, en especial cuando se trata de supuestos de hecho en los que se han vulnerado frontalmente derechos humanos. De ahí que sea preciso modular los métodos de justicia transicional; indudablemente porque carece de legitimidad y justificación si se aplican ignorando unos estándares nucleares o mínimos de los derechos fundamentales constitucionalizados, o de esos mismos derechos consagrados en un plano convencional/internacional.

La justicia transicional «hacia la paz» es el resultado de un acuerdo de naturaleza política, cuya implementación requiere la creación de un marco jurídico especial ${ }^{13}$. El problema reside principalmente en delimitar los efectos que produce, así como los requisitos y condiciones que afectan a los dispositivos jurisdiccionales y sancionatorios que implica su puesta en práctica, y en especial en la relación que se entabla con el principio de constitucionalidad, cuya supremacía no puede ser eludida en ningún caso. Lo contrario supondría la apertura indirecta de un nuevo e "implícito" pacto constituyente, que se activa sin tener en cuenta los procedimientos de reforma tasados en la norma fundamental del Estado.

Así pues, como sostiene Ferrajoli (2016: 146-161), la «justicia transicional» se erige como un modelo de justicia necesaria para garantizar una «transición a la paz». Sobre esta identificación sustancial — justicia transicional y justicia para la paz- se conforma lo que sería su fundamental objetivo y

13 Efectivamente, partiendo de su carácter esencialmente político, los Acuerdos de Paz contienen en potencia una indudable normatividad que se proyectaría en un triple sentido: sobre las potestades presidenciales que podrían implementarlos; en la medida en que algunos de los compromisos adquiridos requerían la intervención legislativa del Parlamento, y finalmente, porque algunos de esos acuerdos exigían para su ejecución una reforma constitucional (Franco Osorio y Luján Devoz, 2017: 234). Pese al esfuerzo por dotar de eficacia jurídica vinculante a los Acuerdos, lo cierto es que esta última solo se adquiría mediante las reformas administrativas, legislativas y constitucionales que garantizaban su integración plena en el ordenamiento de un Estado de derecho como el colombiano. 
razón de ser. La existencia de una justicia transicional se justifica por el hecho de ser aplicada en un contexto político específico, como un instrumento que — temporal en su aplicación — favorece el tránsito en un contexto de especial trascendencia política y social.

La prioridad de la justicia transicional viene marcada por la consecución de un objetivo político, articulado en torno a la pacificación de una sociedad en conflicto y el reconocimiento y la garantía de los derechos de las víctimas. En ese sentido, la recuperación de la verdad se convierte en un requisito necesario para alcanzar la reconciliación de los sectores sociales enfrentados ${ }^{14}$.

La justicia transicional corre sin duda riesgos. Seguramente uno de los más sobresalientes tiene que ver con su eventual percepción como fórmula implícita con la que se logre la impunidad de quienes son culpables de actuaciones delictivas; en suma, una especie de amnistía encubierta ${ }^{15}$ potencialmente antagónica con el valor de la dignidad de los principales afectados por la violación de sus derechos fundamentales.

Entre los puntos de potencial colisión de la justicia transicional con una concepción que podríamos adjetivar ahora de derechos constitucional «tradicional», cabría destacar la que se puede producir entre las versiones material y positiva del principio/valor de la justicia ${ }^{16}$; y especialmente, la tensión por su potencial incompatibilidad con el derecho a la tutela judicial, visto este último desde una perspectiva y comprensión eminentemente jurisprudenciales. Así

14 Sobre la importancia de la verdad, parece difícil imaginar que se llegue a producir una verdadera y sólida reconciliación social, sin que se haya hecho un reconocimiento público y explícito por sus culpables de los hechos que hayan causado daños en los derechos e intereses de las víctimas. La obtención de la verdad se convierte así en un instrumento de la justicia transicional que permite alcanzar un «resarcimiento moral» —diferente del concepto tradicional de «daño moral»— con el que las víctimas se pueden sentir compensadas en parte por la lesión que han sufrido en sus derechos. No obstante, la propia Constitución colombiana proporciona cobertura jurídica a la posible aprobación de indultos que tengan un carácter colectivo, cuando en su art. artículo. 150 (n. 17) autoriza al Congreso para "conceder, por mayoría de los dos tercios de los votos de los miembros de una y otra Cámara y por graves motivos de conveniencia pública, amnistías o indultos generales por delitos políticos. En caso de que los favorecidos fueren eximidos del responsabilidad civil respecto de particulares, el Estado quedará obligado a las indemnizaciones a que hubiere lugar».

16 Utilizando el apoyo argumental que proporciona la Sentencia 20/1987 del Tribunal Constitucional español, se puede afirmar que el valor superior de justicia no puede entenderse al margen o de forma contrapuesta al ordenamiento positivo, hasta tal punto que pueda posibilitar el decaimiento de otra norma constitucional a favor de una determinada «justicia material» (Martínez Ruano, 2018: 37). 
pues, ni la bipolaridad del valor constitucional de la justicia ni las diferentes dimensiones que configuran el derecho fundamental antes citado pueden ser obviadas con la adopción de un sistema especial de justicia transicional.

El catálogo de principios que derivan y en los que se fundamenta un Estado de derecho es de tal calibre constitucional que impide otorgar a aquella una prevalencia automática y sin las convenientes ponderaciones, todas ellas enmarcadas en la esfera de sus principios fundamentales: principio de legalidad (penal), seguridad jurídica, irretroactividad de las normas sancionatorias (y su versión inversa, como posible derecho a la retroactividad de las normas más favorables), sin olvidar tampoco los criterios de interpretación hoy generalizados como el de proporcionalidad y razonabilidad en la regulación y aplicación de las sanciones penales. De igual modo, es ineludible conciliar el derecho a la tutela judicial con la necesidad de garantizar en la esfera jurisdiccional los derechos de las víctimas; su naturaleza poliédrica exige, por tanto, una evaluación de los distintos planos en los que se compone este derecho jurisdiccional ${ }^{17}$.

Por razones como las anteriormente indicadas, la justicia transicional no puede llevarse a cabo sin la necesaria adaptación del orden constitucional. Este último desempeña un papel esencial de legitimación desde el cual se suministra la necesaria cobertura jurídica a la hora de adoptar los mecanismos procesales y disposiciones penales extraordinarios. De ahí que la «ductilidad» propia de las normas constitucionales, según Zagrebelsky, se presente como un elemento positivo en la operación de implementar los dispositivos excepcionales de este modelo especial de justicia. Estos imponen la necesidad de poner en marcha los procedimientos de revisión del texto constitucional ${ }^{18}$, con

17 Esos planos o dimensiones procesales fundamentales del derecho a la tutela judicial son perfectamente reconocibles en el art. 29 de la Constitución colombiana: debido proceso, principio de legalidad, retroactividad de la «ley permisiva o favorable», presunción de inocencia, asistencia letrada, derecho a un proceso sin dilaciones indebidas, principio contradictorio, derecho al recurso.

Las situaciones de excepcionalidad constitucional han sido reguladas en los textos constitucionales con la finalidad para hacer frente a aquellas circunstancias que ponen en peligro el funcionamiento de las instituciones de un Estado democrático; mediante la declaración de algunos de esos estados de riesgo para la vigencia del orden constitucional se acepta la restricción temporal o suspensión de algunos de los derechos fundamentales. En cierto modo la justicia transicional implica también la aprobación de medidas de ese mismo carácter excepcional y temporal con las que se intenta resolver un escenario de limitación de derechos. Quizá la diferencia entre ambos modelos estriba en que la justicia de transición parece pensada no solo para volver a una situación de «normalidad constitucional», asegurando de este modo el ejercicio de los de- 
la intervención en su caso del propio titular de la soberanía. En este sentido, una norma constitucional excesivamente rígida en sus posibilidades de reforma puede dificultar la aplicación de los dispositivos procesales y punitivos de la justicia transicional.

Alternativamente a los procedimientos que implican el ejercicio directo del poder constituyente, cabe igualmente recurrir a las Altas Cortes (Suprema ordinaria y Constitucional) para que, en el ejercicio de sus competencias de control de constitucionalidad, adopten aquellos criterios de modulación (Sagüés, 2014) que permitan adaptar a esas circunstancias extraordinarias el significado de los principios fundamentales que configuran el Estado constitucional de derecho; incluso si esa función «interpretativa» jurisprudencial pueda producir como resultado —inmediato o colateral — una mutación constitucional.

Pero como todo principio, valor o derecho de naturaleza constitucional, la justicia transicional no puede construirse sin que se hayan fijado unos límites aplicativos, sobre los cuales se configuran sus competencias materiales y subjetivas. En definitiva, la Constitución se erige en la coordenada esencial y el parámetro normativo insuperable a la hora de articular la justicia transicional. Ciertamente los derechos de las víctimas representan en este escenario un compromiso prioritario a la hora de resolver el potencial conflicto interno que se puede llegar a producir con algunos de los principios fundamentales del Estado constitucional. En concreto, la colisión es casi inevitable con el principio democrático de la soberanía popular, en el que pueden encontrar fundamento medidas políticas y legislativas para aplicar los dispositivos de la justicia transicional.

Un segundo canon jurídico (y ético) de referencia, imprescindible a la hora de establecer el alcance y los límites del modelo viene definido en un conjunto de normas contenidas en lo que podríamos denominar como el «bloque convencional» de la justicia transicional. Se localiza en los tratados internacionales sobre derechos humanos y derecho humanitario, completados por las doctrinas jurisprudenciales que emanan de las Altas Cortes internacionales encargadas de su aplicación. Su valor resulta prioritario; aunque no preferente, en el hipotético caso de contradicción —o falta de «diálogo»— con el que suministra la interpretación efectuada por la Corte constitucional. La Constitución, a fin de cuentas, es siempre la norma que otorga la imprescindible

rechos constitucionales al conjunto de la de la sociedad, y a las víctimas en particular; también aspira a integrar en el sistema democrático y jurídico del Estado justamente a quienes han atentado contra el orden constitucional y han generado esas mismas situaciones de peligro o limitación de derechos. 
cobertura y efectividad jurídicas a la aplicación de las obligaciones que se adquieren en la esfera internacional.

El marco normativo para la paz, si bien está fundado sobre principios constitucionales basilares de un Estado de derecho, tiene que complementarse con la remisión y cumplimiento de unos parámetros normativos que derivan de aquel derecho supranacional o convencional (Duque, 2015: 207). Es ineludible por tanto tomar en consideración, como garantía de objetividad, las construcciones doctrinales que emanan sobre este tema de la jurisprudencia de la Corte Interamericana de Derechos Humanos. Sus resoluciones no solo constituyen una medida complementaria de legitimidad «internacional»; también resultan de extraordinaria importancia a la hora de reconocer de qué modo afecta a derechos humanos nucleares la adopción de mecanismos propios de una justicia transicional: el derecho a la verdad (jurídica y material), el derecho a la justicia (como acceso además a la acción de los tribunales de justicia) o el derecho a la reparación (como derecho a recibir una compensación económica) (Quinche Ramírez y Peña Huertas, 2014: 208) ${ }^{19}$.

Desde la esfera constitucional y convencional se estarían marcando unos límites jurídicos a las medidas procesales y sancionatorias excepcionales que conlleva la justicia transicional. Desde un punto de vista objetivo o material, posiblemente la principal restricción es la que fija como delimitación de su competencia jurisdiccional la comisión de determinados crímenes, especialmente graves en cuanto a la vulneración de derechos y principios del derecho humanitario (delitos de genocidio, crímenes de guerra o lesa humanidad). Al margen de que la razón de esta exclusión haya quedado o no explicitada, cabe presumir que la gravedad punitiva de esos actos impide aplicar cualquier tipo

19 La compatibilidad con los parámetros normativos y jurisprudenciales del modelo alternativo de sanciones que conlleva la justicia transicional ya fue puesta de relieve por la Corte Constitucional en su importante Sentencia C-579 de 2013: «Las penas alternativas y los mecanismos especiales para el cumplimiento de la pena como mecanismos ordinarios o de justicia transicional son plenamente aceptados por la comunidad internacional y además han sido estudiados precisamente por esta Corporación, llegando a la conclusión de que no vulneran ninguna norma constitucional, por lo cual menos aún pueden considerarse como una sustitución de la Constitución. Estos mecanismos se fundan en la necesidad de hacer compatibles la justicia con la reconciliación y la no repetición de las conductas a través de sistemas que estén enfocados en la finalidad preventiva de la pena más allá de la retribución. Sobre este aspecto debe resaltarse que desde la sentencia C-144 de 1997 esta Corporación ha señalado de manera contundente la finalidad preventiva de la pena y la necesidad de entender que la retribución es un límite pero no una función de la misma». 
de medida de gracia «jurisdiccional», con la que chocaría frontalmente el contenido esencial y mínimo de los derechos fundamentales violados ${ }^{20}$.

La justicia transicional se distancia de los objetivos que caracterizan a la justicia penal ordinaria (o justicia institucional). Se trata de una justicia enfocada no a la "retribución» o al castigo de los culpables, sino principalmente a la «restauración» y la «reparación ${ }^{21} »$. Su finalidad no se centra en la punición o el castigo de quienes han cometido una infracción tipificada por el derecho penal. No obstante, es perfectamente posible la coexistencia y complementariedad con la justicia retributiva de los sistemas judicial y jurídico penal tradicionales.

En este marco de tensión entre justicia y paz, la excepcionalidad del contexto para el que se articula un sistema de justicia transicional y su finalidad esencialmente restaurativa obligan a aceptar una concepción que podría calificarse como «restrictiva» de los principios en los que tradicionalmente se apoya la justicia penal (ordinaria o institucional). Al otorgando una prevalencia a la consecución de la paz y la reconciliación (Gómez-Velásquez y Correa-Saavedra, 2015: 193), no cabe eliminar del todo el riesgo de que aparezcan ciertos problemas de coordinación con la jurisdicción ordinaria, seguramente necesitada de una serie de reformas para no perder su eficacia y legitimidad.

El sistema «alternativo» sancionatorio ${ }^{22}$ que comprende la justicia transicional no gira en torno únicamente a la pena de privación de libertad y otras accesorias a esta última, como por ejemplo la inhabilitación para ejercer cargo

20 La Corte Constitucional colombiana ha tenido ocasión de pronunciarse en varias ocasiones en contra de la validez de algunas medidas con las que el legislador de ese país pretendía relativizar las garantías penales y procesales propias de un Estado de derecho, traspasando así una frontera incompatible con el respeto de los derechos constitucionales. Entre otras, resultan indicativas de esta posición de la jurisprudencia constitucional la Sentencia n. 817 de 2004 (sobre el Acto legislativo n. 2 de 2003, también bautizado como «Estatuto Antiterrorista») y aquellas resoluciones relativas a la declaración de estados de excepción (sentencias 940 de 2002, 70 de 2009 y 252 de 2010 ).

21 Los beneficios procesales y punitivos de la justicia transicional no pueden extenderse a todos los sujetos potencialmente involucrados en delitos cometidos con ocasión del conflicto. Por esta razón, se convierte en imprescindible la operación de delimitar conceptos como «autoridad» o "máximos responsables», para fijar la extensión y límites de la medidas extraordinarias del sistema.

22 Una expresión muy indicativa de la concepción que tiene la Corte Constitucional colombiana sobre el carácter, significado y alcance de la justicia transicional en cuanto modelo judicial y jurídico «alternativo» de justicia se encuentra en la Sentencia C-709 de 2005. 
público $^{23}$. En el eje central de los mecanismos que se diseñan para una justicia transicional cuenta igualmente la idea, simbólica y a la vez estigmatizante ante la sociedad, de los llamados juicios históricos, con los que se consiguen establecer los denominados como «perdones responsabilizantes». En definitiva, la idea justicia transicional no se apoya solo en la afirmación y el fortalecimiento del Estado de derecho, en cuyo marco jurídico se obtiene el reconocimiento de las víctimas en cuanto sujetos de derecho. También desarrolla, con el objetivo último de lograr la pacificación y restablecer la democracia, una importante "función expresiva». Si se toma como referencia el modelo de justicia restaurativa que se está instaurando en Colombia, se puede advertir el significado y objetivo que persiguen en aquel algunas fórmulas y mecanismos «rituales», a través de los cuales se intenta expresar de manera especialmente enfática la voluntad de reconciliación y el reconocimiento de los derechos de las víctimas. Es el caso de las "conferencias restaurativas", audiencias públicas, o rituales de la vergüenza como ceremonias de degradación y de reintegración (Escobar Beltrán, 2017: 117).

Aunque sin duda estamos convencidos de que hay una condición necesaria en la que descansa en último extremo la eficacia real de los instrumentos jurisdiccionales de la justicia transicional. Nos referimos a la realización del principio constitucional de la igualdad en sentido sustantivo o material. Así pues, ningún proceso de paz puede llegar a buen término si no se toma en serio la realización de los compromisos fundamentales implícitos en la fórmula del Estado social de derecho (art. 1, Constitución 1991). La justicia transicional solo puede tener asegurado el éxito si se acompaña de los instrumentos legislativos y de planificación social que promuevan una verdadera «justicia redistributiva ${ }^{24} »$.

23 La Corte ha basado la aceptación de este sistema sancionatorio «alternativo» en el derecho internacional. Un pronunciamiento bastante indicativo de la posición adoptada por la jurisprudencia constitucional colombiana se localiza en su Sentencia C-579 de 2013: «Las penas alternativas y los mecanismos especiales para el cumplimiento de la pena como mecanismos ordinarios o de justicia transicional son plenamente aceptados por la comunidad internacional y además han sido estudiados precisamente por esta Corporación, llegando a la conclusión de que no vulneran ninguna norma constitucional, por lo cual menos aún pueden considerarse como una sustitución de la Constitución. Estos mecanismos se fundan en la necesidad de hacer compatibles la justicia con la reconciliación y la no repetición de las conductas a través de sistemas que estén enfocados en la finalidad preventiva de la pena más allá de la retribución».

24 A ese objetivo apuntan sin duda las numerosas indicaciones que, ya con carácter vinculante para el Estado colombiano, se apuntan en los Acuerdos de Paz de La Habana en torno a la idea de una reforma agraria integral, el despliegue de nuevas políticas 


\section{EL DERECHO CONSTITUCIONAL A LA PAZ COMO PRESUPUESTO LEGITIMADOR DEL PROCESO DE PAZ Y LOS ACUERDOS DE 2016}

La Constitución colombiana de 1991 resulta verdaderamente original en el marco del constitucionalismo iberoamericano al reconocer la paz como un derecho de los ciudadanos de ese país. En primer lugar, «la paz» aparece ya en el preámbulo, configurada como uno los fines esenciales del pueblo colombiano, junto con otros valores y principios en los que se fundamenta la Constitución política (la vida, la convivencia, el trabajo, la justicia, la igualdad, el conocimiento, la libertad). Sin embargo, la más emblemática -y diríamos también rotunda- formulación constitucional de la paz es la contenida en su art. 22: «La paz es un derecho y un deber de obligatorio cumplimiento». Se trata de una cláusula dotada de, no obstante, y a priori, una fuerza jurídica debilitada. Su virtualidad normativa no reside realmente en la propia Constitución. Las posibilidades de que pueda ser ejercitada como un efectivo derecho/deber público subjetivo van a depender en mayor medida de las condiciones políticas que hagan posible la consecución de esa paz, como de las normas que desarrollen aquel compromiso constitucional en un plano legislativo y gubernamental.

Otra de las más significativas referencias constitucionales a la paz $^{25}$ es la que se contiene en el art. 95, donde se van a indicar las principales obligaciones o «responsabilidades» que derivan del reconocimiento de un amplio catálogo de derechos y libertades. Entre esas obligaciones generales o comunes, de carácter y origen constitucional, se hace una mención específica a la de propender al logro y mantenimiento de la paz.

Pero a efectos de evaluar su auténtica condición jurídica, hay que recordar la exclusión que lleva a cabo el art. 85 de este derecho, al delimitar con precisión exacta el ámbito de los derechos a los que el texto constitucional les proporciona una inmediatez aplicativa. Difícilmente se le podría adjudicar

públicas en materia de educación, vivienda y salud para los principales afectados por el conflicto o, finalmente, la activación e incentivación previstas de mecanismos de democracia participativa.

25 Sin dejar de subrayar la importancia sin duda de otras, como por ejemplo la contenida en el art. 67, que señala los fines que inspiran la educación de los colombiano, y entre los cuales se hace hincapié en la paz y otros objetivos que - entendemos - tienen una relación directa con esta última: «La educación formará al colombiano en el respeto a los derechos humanos, a la paz y a la democracia; y en la práctica del trabajo y la recreación, para el mejoramiento cultural, científico, tecnológico y para la protección del ambiente». 
la característica de una eficacia normativa directa de la que goza el conjunto de los denominados como derechos fundamentales; necesita por lo tanto un desarrollo normativo mediante el cual se concrete la posibilidad de una invocación procesal subjetiva o individual.

No obstante, todas las cláusulas que componen la norma fundamental colombiana deben estar cubiertas por el escudo protector del principio de constitucionalidad. Este argumento justificaría por sí solo la necesidad de que el derecho a la paz disfrute también de una virtualidad normativa mínima o «esencial». De ahí que el hecho de que no pueda derivarse del mismo un derecho/deber dotado de inmediatez o autoaplicabilidad directa no significa que carezca totalmente de vinculatoriedad el bien jurídico constitucionalizado (la paz). Por otra parte, cabe sostener que, a día de hoy, las modificaciones constitucionales y reformas legislativas que se han ido aprobando tras la firma de los Acuerdos permitirían - a nuestro juicio - atribuirle ya al "derecho a la paz» un efecto de «inmediatez jurídica». Su potencial alegabilidad jurisdiccional como derecho público subjetivo ha sido reforzada sin duda; al igual que su capacidad de derecho accionable de forma individual frente al Estado, obligado inexcusablemente por lo tanto a intervenir positivamente en favor de la paz.

La proclamación constitucional de un derecho a la paz debe tener una contrapartida lógica en forma de «deber fundamental» del Estado colombiano, en orden a llevar a cabo necesariamente todas las acciones que favorezcan el compromiso marcado en el art. 22. Un mandato de índole constitucional que se sitúa en consecuencia por encima de mayorías políticas coyunturales de naturaleza presidencial o parlamentaria.

En el caso del deber de contribuir a la paz (art. 95.6), parece configurarse una futura obligación cuya virtualidad mayor no se sitúa en la esfera jurídi$\mathrm{ca}$, de la que no puede derivar automáticamente una potencial exigencia de naturaleza individual. La «paz» que se infiere del texto constitucional contiene en sí misma una dimensión colectiva que enmarca en una esfera política su futuro desarrollo infraconstitucional. Resulta por tanto absurdo pretender reclamar al ciudadano colombiano una contribución obligatoria al proceso de pacificación, más allá del deber moral —y no jurídico— que implica una actitud personal de tolerancia y respeto por los valores propios de cualquier democracia constitucional.

Desde otra perspectiva, ante el supuesto axioma «la Paz se puede imponer a la mayoría», será imprescindible circunscribir a qué "mayoría» se refiere o afecta. Porque efectivamente el objetivo constitucional de procurar la paz en la sociedad colombiana puede imponerse frente una mayoría electoral - parlamentaria o presidencial - de carácter coyuntural, que impida el ejercicio colectivo de ese valor/derecho constitucional, o intente sustraerse al cumplimiento de ese mandato constitucional con actitudes pasivas u 
omisivas. Pero al mismo tiempo la obligación constitucional de alcanzar la paz no puede llevarse a cabo con una metodología antagónica con los fundamentos ético-normativos de un Estado constitucional de derecho. El hecho de ser la expresión una mayoría constitucional cualificada (o hipercualificada) suministra a la norma fundamental un plus de legitimidad para bloquear la utilización de medios contradictorios con sus valores y derechos.

Las soluciones legislativas (o estatutarias) siempre van a necesitar en consecuencia de una cobertura constitucional, en un marco normativo superior - en vigor o bien reformado- , para el logro de la paz. Pero tampoco la priorización de la paz como derecho y objetivo constitucionales debiera tener un carácter "absoluto», si se antepone la consecución de ese objetivo a la garantía mínima de unos derechos fundamentales o «nucleares» constitucionalizados. De ahí la necesidad de que se adopten los habituales criterios - legislativos y jurisprudenciales - de ponderación y modulación, como del intento por alcanzar soluciones que se acomoden a los test de razonabilidad y proporcionalidad. Los anteriores representan factores de interpretación obligatoria cuando se encuentran afectados principios y derechos fundamentales de la Constitución.

En el caso Constitución colombiana, ha sido necesario proceder a la revisión de algunas de sus disposiciones para proporcionar la imprescindible legitimidad y cobertura a las iniciativas parlamentarias y presidenciales en orden a conseguir la definitiva pacificación del país. Se trataba de una exigencia para consolidar el proceso de paz. En esta tarea ha sido determinante sin duda la activa intervención de la jurisprudencia constitucional, como instancia de supervisión encargada de controlar el respeto a los principios fundamentales de la Constitución política ${ }^{26}$.

26 En la doctrina de la Corte Constitucional colombiana se localizan algunos pronunciamientos sobre la naturaleza y alcance del «derecho a la paz». Comienza en 1992 (T008) afirmando su condición de derecho colectivo y susceptible en consecuencia de tutela por la vía de la acción popular, si bien no se trata de un derecho del que se pueda predicar «inmediatez» o aplicabilidad directa (sin necesidad de desarrollo normativo previo). En resoluciones posteriores se añaden nuevas dimensiones por la Corte, vinculando la paz con principios y objetivos diversos, desde el Estado democrático o la convivencia pacífica (T-605, 1992) a derechos territoriales de comunidades indígenas. No existe una línea interpretativa jurisprudencial, uniforme ni clara, en la que se reconozca la "fundamentalidad» de este derecho, aunque sí su capacidad para generar obligaciones para el Estado (C-055, 1995). En unas de las resoluciones más relevantes sobre el tema (Cabra Barrera, 2015: 111) — la C-370 de 2006 - se amplifica su núcleo conceptual con nuevos perfiles: derecho y deber subjetivo de cada ciudadano individual, derecho colectivo fundamental cuya titularidad se encuentra distribuida 


\section{LA REFORMA DE LA CONSTITUCIÓN COLOMBIANA PARA LA INCORPORACIÓN DE UN SISTEMA DE JUSTICIA TRANSICIONAL}

El modelo de justicia transicional colombiano responde a las características generales que están presentes en cualquier otro contexto donde haya sido necesaria su implantación: temporalidad, excepcionalidad, carácter eminentemente restaurativo, metodologías judicial y extrajudicial en la aplicación de sanciones, proporcionalidad — que no inmunidad-en las aplicación de penas, intensidad en el reconocimiento de los derechos de víctimas, y en definitiva la búsqueda de una conciliación entre los valores de justicia y paz.

El alcance y significado de este sistema extraordinario de justicia ha sido evaluado en diversos pronunciamientos de la Corte Constitucional ${ }^{27}$, que ha tenido también ocasión de pronunciarse sobre algunos de sus límites. En esta línea ha señalizado expresamente con carácter general una regla básica infranqueable: las medidas jurisdiccionales especiales de la justicia transicional no pueden sustituir los elementos que definen a la Constitución colombiana, ni resultaría legítimo que con ellas se pueda eludir el enjuiciamiento de los crímenes más graves, como el genocidio, y los crímenes de guerra y de lesa humanidad (Sentencia C-579 de 2013).

En todo caso, se trata de un modelo de justicia de transición que cabría adjetivar como "holístico», ya que pretende armonizar instrumentos y fórmulas jurisdiccionales de diferente naturaleza y alcance (reducción de penas, penas alternativas y extrajudiciales), desde un enfoque esencialmente «restaurativo" y de «no repetición», con especial focalización en los derechos de las víctimas. La incorporación del sistema de justicia transicional al ordenamiento colombiano va a tener lugar a través de la revisión de diversas disposiciones

en una variedad de sujetos (Estado, humanidad, los pueblos y los individuos). En otra resolución se ensancha más aún el objeto de este derecho, considerando la paz como un derecho que deriva de la autonomía de la voluntad, un derecho de participación y, finalmente también, un «derecho de crédito» en cuanto que otorga el derecho a poder exigir una acción concreta del Estado.

27 En la siguiente declaración de la Corte Constitucional se definen con bastante claridad los objetivos, la finalidad y la naturaleza excepcional de la justicia transicional: «Una institución jurídica a través de la cual se pretende integrar diversos esfuerzos, que aplican las sociedades para enfrentar las consecuencias de violaciones masivas y abusos generalizados o sistemáticos en materia de derechos humanos, sufridos en un conflicto, hacia una etapa constructiva de paz, respeto, reconciliación y consolidación de la democracia, situaciones de excepción frente a lo que resultaría de la aplicación de las instituciones penales corrientes». Sentencia C-771 de 2001, citada por Vega Dueñas (2018: 111-130). 
de la Constitución de 1991. El primer eslabón de este proceso de reformas se contiene en el Acto Legislativo 1 de 2012, aprobado por el Congreso de la República, con el que se decretaba la incorporación del nuevo artículo transitorio (art. 66). Las previsiones generales que se hacían allí serían desarrolladas más tarde, una vez firmados los acuerdos con la guerrilla y comenzada ya la etapa de posconflicto, en el Acto legislativo de 1 de abril de 2017, con el que se añade un nuevo título transitorio al texto constitucional. Con el título «Normas para la terminación del conflicto armado y la construcción de una paz estable y duradera», esta segunda iniciativa del Congreso articula el llamado Procedimiento para la Paz.

Esta segunda reforma constitucional prevé la creación de un Sistema Integral de Verdad, Justicia, Reparación y No Repetición (SIVJRNR), cuyas líneas de acción se proyectan en un catálogo de iniciativas de carácter estructural y finalista. Entre las primeras, se incluye la institucionalización de una Comisión para el Esclarecimiento de la Verdad, la Convivencia y la No Repetición y una Unidad para la Búsqueda de Personas dadas por Desaparecidas y la Jurisdicción Especial para la Paz. Como acciones encaminadas a consolidar el proceso de paz se prevén medidas de reparación integral para la construcción de paz y las garantías de no repetición.

Entre los objetivos fundamentales del Sistema Integral (SI) diseñado por el nuevo el título transitorio de la Constitución se encuentra una prioridad, «el reconocimiento de las víctimas como ciudadanos de derechos». A nuestro modo de ver, se trata en el fondo de una enfatización con la que se intenta acentuar la necesidad de que el Estado preste una atención especial a quienes han sufrido —o todavía sufren- un deterioro importante en los niveles de garantía y satisfacción de los derechos constitucionales; ciertamente las víctimas no dejan de ser, como el conjunto de la población, «ciudadanos de derechos».

Desde el punto de vista subjetivo, el sistema se proyecta entonces sobre aquellas minorías de la población que ha experimentado algún tipo de restricción o violación de sus derechos constitucionales como consecuencia del conflicto. La condición específica de las víctimas es trascendental para el reconocimiento de unos derechos singulares - y en cierto modo exclusivosque derivan directamente de violaciones de otros derechos durante el conflicto armado: derechos a la verdad, la justicia, la reparación y a la no repetición. Aunque algunos de estos derechos se pueden localizar ya en el catálogo original de derechos constitucionales (tutela judicial ${ }^{28}$, derecho a la indemniza-

28 La tensión inevitable con el derecho a la tutela judicial de las víctimas se resuelve - en nuestra opinión - favorablemente cuando se incorporan por el acto legislativo 
ción), adquieren ahora un significado específico, en la medida en que resulta excepcional también el contexto (sociopolítico) donde tiene que garantizarse su ejercicio.

Junto con este catálogo de objetivos fundamentales, el artículo transitorio integra también la responsabilidad como principio de naturaleza constitucional. La expresión que emplea el constituyente colombiano no facilita a priori su determinación objetiva, en la medida en que no se llega a precisar a qué clase de responsabilidad estaría haciendo referencia a priori. Debemos presumir al menos que se trata de una modalidad jurídica (y no política) que engloba la derivada de actos ilícitos (responsabilidad penal), y no tanto la responsabilidad de carácter civil o indemnizatorio. Sí se delimitan de forma bastante amplia los destinatarios del concepto constitucional. En este sentido adquieren la condición de responsables todos los que participaron en el conflicto de forma directa o indirecta; aunque en este segundo caso no se contiene ninguna indicación que aclare la condición de responsable indirecto frente a una violación grave de los derechos fundamentales.

En todo caso, resulta más preciso el enunciado de la norma constitucional a la hora de definir las causas que delimitan la atribución de esa responsabilidad. La línea fronteriza que ampara la potestad $-\mathrm{y}$ deber al mismo tiempo- del Estado para exigirla queda delimitada por la realización de lo que se consideran graves violaciones a los derechos humanos y graves infracciones del derecho internacional humanitario. Pese a que los parámetros constitucionales han sido establecidos con una cierta claridad, su aplicación va a requerir de la ayuda de aquellos intérpretes jurisprudenciales que, desde la esfera convencional e internacional, han configurado los parámetros necesarios para concretar el alcance de su aplicación: ámbito objetivo (derechos humanos, derecho humanitario), presupuesto fáctico y jurídico (violación, infracción), y potenciales elementos de modulación (gravedad suficiente).

previsiones del siguiente tenor: «Las normas que regirán la Jurisdicción Especial de Paz, incluirán garantías procesales, sustanciales, probatorias y de acceso, encaminadas a que las víctimas puedan satisfacer sus derechos a la verdad, justicia y reparación en el marco de la JEP con medidas diferenciales y especiales para quienes se consideren sujetos de especial protección constitucional. Igualmente, deberán garantizar los principios de tratamiento penal especial condicionado a la garantía de los derechos de las víctimas, centralidad de las víctimas, integralidad, debido proceso no regresividad en el reconocimiento de derechos y enfoque diferencial y de género». En el caso de miembros de la fuerza pública, la compatibilidad y «sujeción estricta» al art. 29 de la norma fundamental constitucional, donde se han constitucionalizado las principales garantías del proceso penal, quedan aseguradas en lo que se refiere a la «calificación jurídica» de las resoluciones que adopte la JEP (art. 22 del título transitorio). 
Conviene subrayar que la reforma constitucional que incorpora el nuevo título transitorio señala un mandato bastante explícito sobre la obligación de que todos y cada uno de los «componentes» del Sistema Integral se configuren bajo unos «enfoques» y principios fundamentales: participación transversal y transparencia, variables de género y diversidad étnico-cultural y territorial; si bien se hace hincapié en la voluntad de asegurar la protección de unas víctimas especialmente vulnerables, como son mujeres e infancia.

Los anteriores presupuestos metodológicos van a proyectarse después en el proceso de implementación de los Acuerdos, específicamente en cada una de las acciones y estructuras organizativas programadas para el posconflicto. Adicionalmente se aspira a garantizar la independencia del SI mediante la afirmación de su autonomía funcional, que se proyectaría tanto en un plano administrativo como financiero; precisamente para asegurar que esta suficiencia presupuestaria contempla la adopción de unas previsiones presupuestales en un Plan de Inversiones para la Paz (art. 3).

Uno de los componentes de justicia transicional que implanta el nuevo título transitorio es la denominada Comisión para el Esclarecimiento de la Verdad, la Convivencia y la No Repetición. Se trata - y así se establece expresamente- de un órgano dotado de plena autonomía funcional (administrativa, financiera y técnica). Parecía conveniente reforzar esa independencia de instituciones políticas y jurisdiccionales, a la vista de la trascendencia de las competencias que se encomiendan. Además, el éxito del proceso de paz en el posconflicto dependerá en buena medida de la neutralidad de la instancia encargada de investigar y desvelar potenciales responsabilidades que luego se podrán dirimir en la esfera jurisdiccional ${ }^{29}$. De ahí también su ubicación orgánica, externa a las instituciones del Poder Judicial. La fórmula permite, de un lado, actuar con la necesaria libertad en la actividad investigadora que se

29 Desde su condición de órgano «consultivo», esta Comisión tiene capacidad para emitir unas indicaciones, no vinculantes pero realmente trascendentales, sobre unos «criterios de selección», que serán determinantes sin duda del alcance de la justicia transicional (Laiza de Zuluaga Taborda, 2015: 201). En efecto, el nuevo art. 66 enuncia los fines prioritarios que deben cumplir esos criterios, más tarde concretados por la ley estatutaria en función de su gravedad y «representatividad»: «Centrar los esfuerzos en la investigación penal de los máximos responsables de todos los delitos que adquieran la connotación de crímenes de lesa humanidad, genocidio, o crímenes de guerra cometidos de manera sistemática; establecer los casos, requisitos y condiciones en los que procedería la suspensión de la ejecución de la pena; establecer los casos en los que proceda la aplicación de sanciones extrajudiciales, de penas alternativas, o de modalidades especiales de ejecución y cumplimiento de la pena; y autorizar la renuncia condicionada a la persecución judicial penal de todos los casos no seleccionados». 
despliegue para esclarecer las potenciales responsabilidades; al mismo tiempo, respeta el ámbito de fiscalización que debe ser garantizado siempre y en todo caso a los órganos que conozcan después en vía procesal aquellas averiguaciones.

Otro de los componentes institucionales del SI es la llamada Unidad de Búsqueda de Personas dadas por Desaparecidas en el contexto y en razón del conflicto armado (UBPD). Se trata de una entidad "humanitaria y extrajudicial» dotada igualmente de una amplia autonomía funcional y presupuestal. La UBPD se crea con una finalidad esencialmente humanitaria, orientada a la búsqueda de personas desaparecidas, se encuentren con vida o hayan fallecido, durante el desarrollo del conflicto armado. El título transitorio remite a una ley posterior la determinación de su espacio competencial; si bien expresamente puntualiza que en ningún caso las actuaciones que lleve a cabo la UBPD pueden sustituir ni entrar en colisión con la labor investigadora que realicen las autoridades judiciales en los procesos abiertos o en curso. Además, debe garantizar la participación tanto de las víctimas individuales y de las asociaciones que las representen como de los victimarios. Mediante esa doble intervención de los principales afectados por el conflicto se pretende crear un «escenario procesal» en donde sea posible el acercamiento y el diálogo; una colaboración imperativa en el caso del Estado, el cual tiene la obligación — constitucional- de auxiliar a la Unidad en la labor de localización de víctimas desaparecidas ${ }^{30}$.

En el Sistema Integral la Jurisdicción Especial para la Paz (JEP) se erige en un instrumento esencial para controlar el cumplimiento de las condiciones establecidas por el nuevo título constitucional en materia de justicia transicional. Se crea de este modo una instancia de naturaleza jurisdiccional, a la que se dota de unas funciones encaminadas al conocimiento de determinadas conductas que se hubieran realizado durante el desarrollo del conflicto armado.

El título transitorio fija los principios y características fundamentales que deben inspirar el funcionamiento y las especialidades competenciales de esta JEP. De un lado, su carácter temporal, en la medida en que su competencia abarca solo los hechos que se han producido con anterioridad a la firma de los

30 La intervención de las víctimas representa un elemento característico de los procesos de justicia restaurativa de la llamada Jurisdicción Especial para la Paz, incluida en los Acuerdos suscritos en La Habana. Se establecieron entre otras fórmulas de participación: la audiencia o consulta de las víctimas y sus asociaciones representativas en diferentes fases del procedimiento, la legitimación activa para presentar recursos o el reconocimiento para interponer acciones de tutela frente a violaciones de derechos fundamentales. Una visión crítica sobre la indeterminación de esta participación ha sido defendida por Escobar Beltrán (2017: 128). 
Acuerdos de Paz (diciembre de 2016). Asimismo, subraya su carácter preferente y excepcional, circunscribiendo su ámbito jurisdiccional al conocimiento de las conductas que puedan ser constitutivas de «infracciones graves» de las normas del derecho internacional humanitario o de los derechos humanos. Finalmente, se marca un ámbito subjetivo de potencial proyección, limitado a aquellos combatientes que hayan suscrito los Acuerdos de Paz ${ }^{31}$.

Entre los objetivos de la JEP sobresalen conceptos nucleares del posconflicto: justicia, verdad, paz, derechos de las víctimas, seguridad jurídica. Se le otorga asimismo una competencia material y subjetiva que quedaría fuera de la jurisdicción ordinaria. No obstante, en este punto el constituyente ha preferido delegar a una ley parlamentaria posterior para la concreción de sus funciones; será aquella la encargada de establecer los tratamientos penales «diferenciados» aplicables a los sujetos destinatarios y/o beneficiarios de las medidas especiales previstas en aquella; al igual que la delimitación exacta de la frontera competencial entre la JEP y la jurisdicción penal. No obstante, sí que se ha fijado como regla de atribución jurisdiccional que los nuevos delitos que se pudieran cometer después de la firma de los Acuerdos deben ser objeto de conocimiento y enjuiciamiento y quedarán fuera de la JEP.

Las condiciones que se van a exigir para ser beneficiario del trato singular que implica la utilización de las vías procesales de la JEP han sido fijadas de una manera bastante sintética: aportar verdad plena, reparar a las victimas y garantizar la no repetición. Esta triple exigencia se condensa, en realidad y fundamentalmente, en una fundamental: la aportación de la «verdad». Esta condición implica que el relato que se aporte debe cumplir con los parámetros bastante bien definidos en el título transitorio. Por una parte, será necesario describir de forma exhaustiva conductas y circunstancias en que se produjeron las violaciones derechos; aportar igualmente todas las informaciones que sean precisas para la determinación de las responsabilidades jurídicas; si bien esa colaboración para construir el «relato» no presupone la aceptación indirecta de los hechos de los que se informa. En definitiva, la verdad se considera un presupuesto inexcusable para aplicar las medidas especiales de la JEP, ya que sin aquella no se podrían garantizar los derechos de las víctimas a la reparación y la no repetición.

31 La forma de delimitar los sujetos a los que se aplicarán los beneficios de naturaleza procesal y penal tiene como base los principios de la buena fe y la confianza mutua. Su articulación concreta se llevará a cabo con un sistema de «listados» que son objeto de control por parte de un delegado en las llamadas Zonas Veredales Transitorias de Normalización (ZVNT) y los Puntos Transitorios de Normalización (PTN). 
Además del carácter exclusivo y temporal que recae sobre la responsabilidad de ejercitar la JEP, se ha subrayado una norma adicional, útil a la hora de resolver potenciales conflictos con la justicia ordinaria. El título transitorio determina claramente su prevalencia competencia ${ }^{2}$, y en consecuencia también la capacidad para atraer a esta jurisdicción especial todas las conductas o actos que se puedan juzgar en cualquiera de las esferas sancionatorias (penal, administrativa o disciplinaria). En esta línea, y respecto de las sanciones de naturaleza administrativas o disciplinarias — además de las que conlleven efectos patrimoniales o pecuniarios-, la JEP podrá anular y decretar la extinción de responsabilidades; y complementariamente dispondrá de la facultad para someter a revisión aquellas otras que se impusieron como consecuencia de hechos producidos con ocasión del conflicto armado.

El organigrama de la JEP está estructurado en varios órganos con funciones jurisdiccionales y de investigación ${ }^{33}$, que culminan en el denominado Tribunal para la Paz. Este se configura como máxima instancia judicial y órgano de apelación y «de cierre» del sistema; de este modo, en cuanto órgano jurisdiccional con potestad para la revisión de sentencias, dicta resoluciones que adquieren firmeza y, por tanto, son irrecurribles. No obstante, su condición de instancia judicial «superior» en su ámbito material de competencias no impide la interposición de una acción de tutela contra acciones u omisiones

32 Esa preferencia jurisdiccional de los mecanismos y reglas de la justicia transicional en todo lo relativo a la implementación de los Acuerdos de Paz ha sido explícitamente declarada en el art. transitorio 27: «En caso de que con posterioridad a la aprobación del presente Acto Legislativo, se aprobaran leyes o normas que al otorgar tratamientos diferenciados a agentes del Estado o a otras personas por conductas relacionadas directa o indirectamente con el conflicto armado, fueran combatientes o no combatientes, provocaren que los anteriores sean excluidos de la competencia de la Jurisdicción Especial para la Paz, o tuvieren como resultado la inaplicación de dicha jurisdicción o la inaplicación de las condiciones referidas a las sanciones que se recogen en el Acuerdo final de 24 de noviembre de 2016 respecto de dichas personas, el Tribunal Especial para la Paz ejercerá su jurisdicción preferente en las materias de su competencia conforme al presente Acto Legislativo».

33 El art. 7 transitorio articula con una estructura orgánica plural la JEP: Sala de Reconocimiento de Verdad, de Responsabilidad y de Determinación de los Hechos y Conductas; Sala de Definición de las Situaciones Jurídicas; Sala de Amnistía o Indulto; Unidad de Investigación y Acusación, y la Secretaría Ejecutiva, finalizando las diferentes instancias en el Tribunal para la Paz. Destaca asimismo en su composición la aplicación de las variables de género y multiculturalidad, al establecer que deberá estar formada "con criterios de participación equitativa entre hombres y mujeres, garantías de no discriminación y respeto a la diversidad étnica y cultural». 
de la JEP, en el caso de que estas puedan llegar a producir una violación o representen una amenaza a los derechos fundamentales. Se trata de una acción procesal de carácter «subsidiario» en la medida en que se exige haber agotado previamente todos los recursos posibles dentro del sistema jurisdiccional especial como JEP y no exista además otra vía idónea para reaccionar frente a esa violación (art. 8 transitorio). El procedimiento, que cuenta con varias instancias judiciales (secciones de Revisión y de Apelaciones) culmina en la Corte Constitucional; concretamente, en una sala formada por dos magistrados de la propia Corte y dos más de la JEP, y en revisión por la Sala Plena de aquella.

No obstante, la competencia procesal de la jurisdicción constitucional tiene unas limitaciones. De un lado, sus resoluciones tienen una naturaleza básicamente "declarativa»; lo que significa que no pueden «anular, invalidar o dejar sin efectos la decisión del órgano de la Jurisdicción Especial para la Paz» (art. transitorio $8 .{ }^{\circ}$ ); y de otra parte, su legitimación se circunscribe al enjuiciamiento de los hechos y conductas probadas en la acción de tutela, sobre los que ha conocido previamente la Jurisdicción Especial para la Paz. Finalmente, las resoluciones que dicte la Corte deberán ser remitidas al Tribunal para la Paz, donde serán ejecutadas en forma de medidas que este último estime más convenientes para el restablecimiento del derecho vulnerado o amenazado. En todo caso, el artículo transitorio asegura de nuevo lo que constituye en realidad un auténtico monopolio jurisdiccional en esta materia, al otorgar firmeza a esta ejecución e impedir en consecuencia cualquier posible activación posterior de una nueva acción de tutela.

En lo que respecta a la aplicación de sanciones, y cuando no sea viable evitar la incoación de un procedimiento penal, se autoriza al Tribunal para la Paz para decidir sobre la sustitución de las penas que correspondieran por aquellas otras fórmulas sancionatorias características de la JEP. La adopción de este «beneficio» requiere con carácter previo que quien haya sido condenado «reconozca verdad completa, detallada y exhaustiva», además de cumplir con el deber de satisfacción de los derechos de las víctimas (a la reparación y a la no repetición).

\section{EL PAPEL DE LA JURISDICCIÓN CONSTITUCIONAL EN EL PROCESO HACIA LA PAZ Y LA MATERIALIZACIÓN DE LOS ACUERDOS EN EL POSCONFLICTO}

Para la consecución de un definitivo y verdadero «estado de paz» en Colombia la Corte Constitucional se erige en una institución trascendental durante la presente etapa de posconflicto (Maldonado, 2013); sea en su calidad de garante y supremo intérprete de la norma constitucional de 1991, como de 
institución encargada de supervisar la corrección constitucional de las iniciativas que se lleven a cabo en la esfera legislativa.

Las funciones mencionadas fueron ya ejercitadas con motivo de la aprobación de la reforma constitucional contenida en el Acto Legislativo 1 de 2012, cuya finalidad primordial era proporcionar una cobertura constitucional a los mecanismos de justicia transicional, a la vez que marcar la orientación prioritaria — los derechos de las víctimas - que debía orientar su implementación.

Sobre el alcance y los límites constitucionales de los instrumentos de justicia transicional, los pronunciamientos más relevantes de la Corte Constitucional colombiana se localizan en las Sentencias C-579 (2013) I y C-577 (2014). Su posición sobre el Acto Legislativo 1-2012 fue en general favorable a la exequibilidad del nuevo art. 66 transitorio (inciso primero) de la Constitución (Ambos, 2013). La jurisprudencia constitucional se pronunciará favorablemente sobre la compatibilidad de los métodos de la justicia transicional con algunos de los principios del Estado social y democrático de derecho, y en concreto con "los derechos de la sociedad y las victimas». La Corte utiliza para ello una técnica de ponderación entre derechos y principios constitucionales: derecho a la paz, reconciliación, derechos a la reparación, a la verdad y a la justicia.

Desde esta premisa la jurisprudencia constitucional sostiene la validez constitucional de medidas procesales enfocadas a la selección y priorización establecidaqs en el Acto Legislativo, así como del sistema de «macroprocesos» previstos para el enjuiciamiento de graves violaciones de derechos humanos. Valida también otras medidas como la suspensión condicional de las penas, la imposición de sanciones extrajudiciales y alternativas y otras modalidades especiales de cumplimiento de penas.

En opinión de la Corte, este catálogo de instrumentos de justicia transicional no entra en colisión con los que denomina "pilares de la Carta»; como tampoco se opone frontalmente a los instrumentos convencionales sobre derechos humanos y derecho humanitario ratificados por el Estado colombiano. No obstante, se van a señalar unas condiciones que necesariamente deben cumplirse para garantizar los derechos de las víctimas. Se trata unas veces de exigencias de carácter procesal, como las que se imponen para otorgar una prioridad a la solución de casos especialmente graves, o bien de naturaleza política (desmovilización efectiva y entrega de las armas).

La compatibilidad constitucional se predicará también por la Corte en relación con los mecanismos de integración y participación políticas de los miembros de grupos armados (art. 3 del Acto Legislativo de 2012, como nuevo art. 77 constitucional). La reforma constitucional de 2012 incluía un nuevo art. 67 que reconocía la posibilidad de que, una vez llevada a efecto la desmovilización, 
los miembros de los grupos armados pudieran participar en el sistema político del Estado colombiano, salvo que estuvieran implicados en crímenes de lesa humanidad y genocidio. La Sentencia C-577 (2014) considera que no existía contradicción con el principio de participación política de la Constitución de 1991 (arts. 179-1, 197.2, 232.3 y 259.3), de modo que la condena por delitos políticos no implicaba una inhabilitación para el ejercicio de cargos públicos de elección popular.

La legitimidad de la justicia transicional queda garantizada siempre que tenga como finalidad primera y prioritaria conseguir una paz estable. Desde esta premisa, la Corte valida la constitucionalidad de medidas como la suspensión de penas o la aplicación de penas alternativas, extrajudiciales y especiales. No obstante, las fórmulas procesales y punitivas implantadas en un marco de justicia transicional estarán en todo caso limitadas por la obligación de las autoridades estatales de asegurar el procesamiento y condena de los sujetos involucrados en delitos que supongan una vulneración frontal de principios fundamentales del derecho humanitario (delitos de lesa humanidad, guerra y genocidio). De igual modo el Estado colombiano no dispone de una discrecionalidad absoluta para su activación; en este sentido, la Corte señaliza los requisitos bastante precisos que se deben de cumplir: transparencia, objetividad de la investigación, posibilidad de activar recursos, asesoría especializada, el respeto por el derecho a la verdad o la reparación integral.

Otra de las resoluciones jurisprudenciales más importantes y que han marcado el posconflicto colombiano ha sido la Sentencia C-379/16 (de 18 de julio de 2016), que gira en torno al problema del valor y la validez constitucional del referéndum como instrumento de participación política con el que sancionar los Acuerdos de Paz (Franco Osorio y Luján-Devoz, 2017: 249). En este caso, la Corte se posiciona nítidamente al declarar la eficacia exclusivamente política de la consulta; sin que se pueda otorgar ningún efecto vinculante, desde un punto de vista jurídico, a los resultados que se obtengan en cuanto a participación popular y sentido del voto. La sentencia advierte además la imposibilidad de que esa consulta referendaria pueda forzar por sí misma una reforma de la Constitución.

En lo que respecta a los niveles que se habían previsto en los instrumentos legislativos que regulaban la consulta (Proyecto de Ley estatutaria 94/15, Senado 156/15 Cámara) para considerar aprobado el plebiscito, la Corte Constitucional estima que el mínimo alcanzado superaría positivamente los test de «proporcionalidad» y «representatividad». De igual modo, reconoce que el referéndum solo puede vincular al órgano que lo convoca (presidente) - $-\mathrm{y}$ no a las demás instituciones y poderes del Estado-, ya que se trata de una función radicada constitucionalmente de manera exclusiva en la esfera competencial presidencial. Desde esta concepción casi exclusivamente 
«funcional» del plebiscito, la jurisprudencia constitucional colombiana admite la facultad del presidente - y otros órganos del Estado- para explorar otras vías alternativas en el caso de que no se alcancen los estándares de participación y aceptación establecidos legalmente.

Por otro lado, el procedimiento diseñado para la elaboración de normas que permitan la ejecución del Acuerdo de Paz ha sido objeto también de examen por la jurisprudencia constitucional colombiana. El denominado fast track —o también «Procedimiento Legislativo para la Paz»—, creado por el Acto Legislativo 1/2016, pretende establecer un sistema ágil y singular de aprobación parlamentaria de las iniciativas impulsadas por el Gobierno, al que se otorga durante esta fase inicial del posconflicto un protagonismo político indiscutible para la implementación de los Acuerdos. En primer lugar, esas especialidades procedimentales se van a aplicar tanto a los proyectos de ley como a los actos legislativos. El Ejecutivo nacional parece disfrutar en ambos casos de una posición hegemónica sobre el Parlamento; no solo porque se le reserva la capacidad de impulso e iniciativa, sino además por el hecho de que sus propuestas gozan de preferencia para ser tramitadas en el Congreso.

Otra de las decisiones de mayor magnitud jurídica para la implementación de los Acuerdos de Paz se contiene en el Acto Legislativo 1/2016 (procedimiento del denominado fast track), al confirmar este último de manera expresa la naturaleza "cuasiconstitucional» del Acuerdo Final para la Terminación del Conflicto y la Construcción de una Paz Estable y Duradera ${ }^{34}$. Su inclusión en el denominado «bloque de constitucionalidad» supondrá la adopción de un parámetro supralegal de validez frente a los proyectos legislativos que se promuevan por el Ejecutivo presidencial y el Congreso; o lo que es lo mismo, la implantación de potenciales restricciones y condiciones a la autonomía parlamentaria. El Congreso no puede quedar excluido en esta fase de ejecución de los Acuerdos de Paz, en la medida en que estos tienen que articularse mediante una Ley aprobatoria del Acuerdo especial. Sin embargo, en el control de —automático y único- que pueda realizar la Corte Constitucional el texto de los Acuerdos se transforma entonces en verdadero canon de constitucionalidad.

34 El texto del nuevo "artículo transitorio» que se propone a la Constitución de 1991 no deja margen a la duda sobre la definitiva y directa "constitucionalización" de los Acuerdos de Paz: «En desarrollo del derecho a la paz, el Acuerdo Final para la Terminación del Conflicto y la Construcción de una Paz Estable y Duradera constituye un Acuerdo Especial en los términos del artículo 3 común a los Convenios de Ginebra de 1949. Con el fin de ofrecer garantías de cumplimiento del Acuerdo Final, una vez éste haya sido firmado y entrado en vigor ingresará en estricto sentido al bloque de constitucionalidad para ser tenido en cuenta». 
La decisión de la Corte Constitucional (Sentencia C-699/16) va a resolver en un sentido positivo o favorable las especialidades en el procedimiento legislativo previstas en este fast track. Defiende que esa modificación de las reglas del iter legislativo ordinario contenidas en la norma constitucional no puede ser equiparada a una modificación encubierta o indirecta del procedimiento de reforma constitucional, ya que en ese caso se estaría vulnerando el principio básico de la rigidez constitucional.

En cuanto a la potencial vulneración que se producía del principio de separación de poderes, al conferir al presidente unas potestades excepcionales, y con una elevada dosis de indeterminación y generalidad, la posición de la Corte es favorable a esta concesión, justificada en la necesidad de impulsar la ejecución de los acuerdos. Porque para la jurisprudencia constitucional estas no suponen transferir a su esfera competencial funciones que corresponden, por prescripción constitucional, al Congreso. Como lo demuestra además el dato de que este último conserva siempre la facultad para anular la delegación de esas facultades extraordinarias, atrayendo de nuevo a su ámbito competencial el ejercicio de las mismas. El principio de separación de poderes no quedaría por tanto eliminado, por la posible habilitación — limitada y temporal (180 días) — que pueda realizar el Parlamento. Más aún si mantiene intacta la potestad para modificar el contenido de los decretos presidenciales, junto con la eventual posibilidad de activar un control de constitucionalidad del producto normativo a que haya dado lugar la delegación.

La jurisprudencia constitucional se pronuncia también sobre la noción «refrendación popular», un instrumento que previsto en el Acto Legislativo para validar las modificaciones que se propusieran al texto constitucional. En este aspecto la Corte realiza una interpretación "contextualizada», desde la cual llega a una conclusión positiva sobre la constitucionalidad de la norma. Esa jurisprudencia adaptada viene en gran medida impuesta por las circunstancias políticas que genera el rechazo popular del plebiscito de 2 de octubre (2016). La ausencia de facto de una sintonía en los resultados que arrojó la utilización de este instituto de democracia directa, respecto de lo acordado por las instituciones representativas de la misma ciudadanía (presidente y Congreso), va a conllevar a la postre una versión devaluada de los primeros, sancionada por la propia Corte.

La jurisprudencia constitucional aceptará en este sentido la sustitución del pronunciamiento popular, a través de un mecanismo referendario, por la decisión adoptada finalmente por los poderes del Estado, dotados de competencias constitucionales para el desarrollo e implementación de los Acuerdos de Paz. De este modo, la Corte admitirá las singularidades en el procedimiento parlamentario para la aprobación de los actos y proyectos normativos que implementarán los acuerdos de paz en el posconflicto. Una excepcionalidad 
(mayoría absoluta, cuatro debates) y transitoriedad (seis meses) que —a su juicio- no sería correcto interpretar como la equiparación con el procedimiento de reforma constitucional, el cual necesita siempre de una confirmación referendaria no prevista para la aprobación de la leyes ordinarias ${ }^{35}$.

\section{Bibliografía}

Ambos, K. (ed.) (2013). Justicia de Transición y Constitución. Análisis de la sentencia C-579 de 2013 sobre el Marco Jurídico para la Paz. Bogotá: Temis.

Cabra Barrera, S. A. (2015). La paz como derecho fundamental y humano. Una propuesta para el retorno de la vía judicial como mecanismo de garantía y protección. Disponible en: https://bit.ly/2zg18Hp.

Díaz Gamboa, L. B. (2016). La paz en Colombia: entre el acuerdo, el desacuerdo y el desespero. Cuadernos Manuel Giménez Abad, 12, 150-158.

Duque Ayala, C. (2016). Los procesos de justicia transicional, justicia, verdad y reconciliación en el espacio Francófono y en América Latina. IUSTA, 2 (45), 19-44. Disponible en: https://doi.org/10.15332/s1900-0448.2016.0045.01.

Duque, C. (2015). El control constitucional de la justicia transicional en Colombia, frente a los requerimientos de la Corte Interamericana de Derechos Humanos. Verba Iuris, 33, 77-97.

Escobar Beltrán, A. A. (2017). Reflexiones criminológicas sobre la justicia retributiva y restaurativa de cara a la función expresiva de la justicia transicional. En J. C. Forero Ramírez (coord.). Justicia transicional en Colombia: un nuevo camino hacia la Paz. Valencia: Tirant lo Blanch.

Ferrajoli, L. (2016). La justicia penal transicional para la Colombia del posconflicto y las garantías para la paz interna. Crítica Penal y Poder, 10, 146-161.

Franco-Osorio, A. G. y Luján-Devoz, M. A. (2017). Un nuevo camino hacia la paz (II): análisis jurídico del acuerdo y sus mecanismos de refrendación. En J. C. Forero Ramírez (coord.). Justicia transicional en Colombia: un nuevo camino hacia la paz. Valencia. Tirant lo Blanch.

Gómez-Velásquez, A. y Correa-Saavedra, J. (2015). ¿Sobredimensión de la tensión entre justicia y paz? Reflexiones sobre justicia transicional, justicia penal y justicia restaurativa en Colombia. International Law: Revista Colombiana de Derecho Internacional, 13 (26), 192-248.

35 Como hemos sostenido en otro lugar (Ruiz-Rico, 2018), de lo que no estamos seguros, sin embargo, es del efecto validador que desde un punto vista estrictamente constitucional tendría la refrendación popular del Acuerdo Final para la Paz. Se le parece estar otorgando una eficacia legitimadora automática, gracias a la cual las iniciativas y proyectos legislativos que se adopten en el futuro quedarían amparados constitucionalmente por la utilización de este método de participación popular. 
Huérfano-Rueda, L. A. y Isaza-González, N. (2017). Un nuevo camino hacia la paz: marco jurídico de las negociaciones con las FARC. En J. C. Forero Ramírez (coord.). Justicia transicional en Colombia: un nuevo camino hacia la paz. Valencia. Tirant lo Blanch.

Laiza de Zuluaga Taborda, J. E. (2015), Justicia transicional y criminalidad política. Implicaciones desde el punto de vista del modelo de selección y priorización procesal penal. En K. Ambos y C. Steiner (coords.). Justicia de Transición y Constitución II, análisis de la sentencia c-577 de 2014 de la corte constitucional (pp. 201). Bogotá: Temis.

Maldonado, A. (2013). El rol de la Corte Constitucional en la garantía del derecho a la paz. Universitas Estudiantes, 10, 277-292.

Marquandt, B. (2016). Ius contra bellum: la promoción del potencial humano a la paz mediante el derecho público e internacional. Bogotá: Grupo Editorial Ibáñez.

Martínez Ruano, P. (2018). Justicia transicional y garantía de los derechos constitucionales. En G. Ruiz-Rico, I. Szegedy Maszák y R. A. Prieto Sanjuán (comps.). Retos en la implementación de los Acuerdos de Paz en Colombia (pp. 29-48). Valencia: Tirant lo Blanch.

Olano-García, H. A. (2016). Del conflicto al postacuerdo: actualidad constitucional de la doctrina de la seguridad nacional ante la justicia transicional. DIXI, 18 (23), 9-25. Disponible en: https://doi.org/10.16925/di.v18i23.1288.

Pérez Sola, N. (2018). Tratamiento constitucional de la propiedad privada: la función social e la propiedad como fundamento de una posible reforma rural integral en Colombia. En G. Ruiz-Rico, I. Szegedy Maszák y R. A. Prieto Sanjuán (comps.). Retos en la implementación de los Acuerdos de Paz en Colombia (pp. 327-368). Valencia: Tirant lo Blanch.

Prieto San Juan, R (2018). La jurisdicción especial para la paz: internacional, a pesar de todo... En G. Ruiz-Rico, I. Szegedy Maszák y R. A. Prieto Sanjuán (comps.). Retos en la implementación de los Acuerdos de Paz en Colombia (pp. 131-154). Valencia: Tirant lo Blanch.

Quinche Ramírez, M. F. y Peña Huertas, R. de P. (2014). La dimensión normativa de la justicia transicional, el Sistema Interamericano y la negociación con los grupos armados en Colombia. ACDI: Anuario Colombiano de Derecho Internacional, 7, 113-159. Disponible en: https://doi.org/10.12804/acdi7.2014.04.

Ruiz-Rico, G. (2018). Dimensión y problemática constitucionales de los derechos de paz en Colombia: los derechos constitucionales en el postconflicto. En G. Ruiz-Rico, I. Szegedy Maszák y R. A. Prieto Sanjuán (comps.). Retos en la implementación de los Acuerdos de Paz en Colombia (pp. 327-368). Valencia: Tirant lo Blanch.

Sagüés, N. P. (2014). La modulación constitucional. Manifestaciones en el reciente constitucionalismo latinoamericano. Revista Iberoamericana de Derecho Procesal Constitucional, 21, 277-291. Disponible en: https://bit.ly/2AzrypB.

Vega Martinis, O. H. de la (2017). ¿Juicio al mal radical? Dos reflexiones acerca de la justicia transicional en Colombia. En G. Ruiz-Rico, I. Szegedy Maszák y R. 
A. Prieto Sanjuán (comps.). Retos en la implementación de los acuerdos de paz en Colombia (pp. 19-29). Valencia: Tirant lo Blanch.

Vega Dueñas, L. C. (2018). Modelo de justicia transicional: el caso colombiano. En G. Ruiz-Rico, I. Szegedy Maszák y R. A. Prieto Sanjuán (comps.). Retos en la implementación de los Acuerdos de paz en Colombia (pp. 110-130). Valencia: Tirant lo Blanch. 